\title{
STRUCTURAL VALVE DETERIORATION IN MITRAL REPLACEMENT SURGERY: COMPARISON OF CARPENTIER-EDWARDS SUPRA-ANNULAR PORCINE AND PERIMOUNT PERICARDIAL BIOPROSTHESES
}

W. R. Eric Jamieson, MD

Michel A. Marchand, MD

Conrad L. Pelletier, MDa

Robert Norton, $\mathrm{MD}^{\mathrm{c}}$

Michel Pellerin, $\mathrm{MD}^{\mathrm{a}}$

Thomas W. Dubiel, MD ${ }^{\mathrm{d}}$

Michel R. Aupart, $\mathrm{MD}^{\mathrm{b}}$

Willem J. Daenen, MD

Michael P. Holden, $\mathrm{MD}^{\mathrm{c}}$

Tirone E. David, MD

Eke A. Ryba, MD

William N. Anderson, Jr, $\mathrm{PhD}^{\mathrm{f}}$
Background: Bioprostheses preserved with glutaraldehyde, both porcine and pericardial, have been available as second-generation prostheses for valve replacement surgery. The performance with regard to structural valve deterioration with the Carpentier-Edwards supra-annular (CE$\mathrm{SAV}$ ) porcine bioprosthesis and the Carpentier-Edwards Perimount (CEP) pericardial bioprosthesis (Baxter Healthcare Corp, Edwards Division, Santa Ana, Calif) was evaluated to determine whether there was a difference in mitral valve replacement. Methods: The CE-SAV bioprosthesis was implanted in 1266 overall mitral valve replacements (isolated mitral, 1066; mitral in multiple, 200) and the CE-P bioprosthesis in 429 overall mitral valve replacements (isolated mitral, 328; mitral in multiple, 101). The mean age of the CE-SAV population was $64.2 \pm 12.2$ years and that of the CE-P population, $60.7 \pm 11.7$ years $(P=.0001)$. For the study, structural valve deterioration was diagnosed at reoperation for explantation. Results: The freedom from structural valve deterioration was evaluated to 10 years, and the freedom rates reported are at 10 years. For the overall mitral valve replacement groups, the actuarial freedom from deterioration was significant $(P=\mathbf{. 0 0 0 1})$ : CE-P $>C E-S A V$ for 40 years or younger, $80 \%$ versus $60 \%$; 41 to 50 years, $91 \%$ versus $61 \%$; 51 to 60 years, $84 \%$ versus $69 \%$; 61 to 70 years, $95 \%$ versus $75 \%$. The older than 70-year group was $100 \%$ versus $92 \%$ (no significant difference). The actual freedom from structural valve deterioration also demonstrated the same pattern at 10 years: 40 years or younger, $C E-P$ 82\% versus $C E$ SAV $68 \%$; 41 to 50 years, $92 \%$ versus $70 \%$; 51 to 60 years, $90 \%$ versus $80 \%$; 61 to 70 years, $97 \%$ versus $88 \%$; and older than 70 years, $100 \%$ versus $97 \%$. The independent risk factors of structural valve deterioration for the overall mitral valve replacement group were age and age groups and prosthesis type (CE-SAV > CE-P). The prosthesis type either in isolated replacement or in multiple replacement was not predictive of structural valve deterioration. The pathology of structural valve deterioration was different: $70 \%$ of CE-P failures were due to calcification and $57 \%$ of CE-SAV failures were due to combined calcification and leaflet tear. Conclusion: The actuarial and actual freedom from structural valve deterioration, diagnosed at reoperation, is greater at 10 years for CE-P than for CE-SAV bioprostheses. The mode of failure is different, and the cause remains obscure. Long-term evaluation is recommended, because the different modes of failure may alter the clinical performance by 15 and 20 years. (J Thorac Cardiovasc Surg 1999;118:297-305)
From Vancouver and Toronto, Canada ${ }^{\mathrm{a}}$; Tours Cedex, France ${ }^{\mathrm{b}}$; Tyne and Walsgrave Coventry, United Kingdom ${ }^{c}$; Uppsala, Sweden ${ }^{\text {; }}$; Leuven, Belgium ${ }^{\mathrm{e}}$; and Irvine, Calif. ${ }^{\mathrm{f}}$

Read at the Twenty-fourth Annual Meeting of The Western Thoracic Surgical Association, Whistler, British Columbia, June 24-27, 1998.
Received for publication July 15, 1998; revisions requested Sept 4, 1998; revisions received March 26, 1999; accepted for publication April 8, 1999.

Address for reprints: W. R. Eric Jamieson, MD, Suite 3100, 910 West 10th Ave, Vancouver, British Columbia, Canada V5Z 4E3.

Copyright $\odot 1999$ by Mosby, Inc.

$0022-5223 / 99 \$ 8.00+0 \quad \mathbf{1 2 / 6 / 9 9 2 3 3}$ 
$B^{\mathrm{i} i}$ oprostheses, porcine and pericardial, have been sed for cardiac valve replacement surgery for more than 25 years. The literature provides extensive documentation that structural valve deterioration (SVD) is the major complication of bioprostheses necessitating reoperation. SVD occurs less commonly in older age groups and to a greater degree with mitral prostheses than aortic prostheses.

The freedom from SVD is not different between firstand second-generation porcine bioprostheses. ${ }^{1-3}$ The first-generation pericardial bioprostheses, IonescuShiley (Shiley, Inc, Irvine, Calif) and Hancock pericardial prostheses (Medtronic, Inc, Minneapolis, Minn), were removed from the market in 1987 at the time of requirement for premarket approval because of premature structural failure. The second-generation Carpentier-Edwards Perimount (CE-P) pericardial bioprosthesis (Baxter Healthcare Corp, Edwards Division, Santa Ana, Calif) has now been used for approximately 15 years. Numerous publications have documented the freedom from SVD for aortic valve replacements for both the CE-P and second-generation porcine bioprostheses, especially the Carpentier-Edwards SupraAnnular (SAV) and Hancock II porcine bioprostheses, but no formal comparison has been undertaken. ${ }^{4-19}$ The performance of the CE-P and the second-generation porcine bioprostheses with regard to SVD for mitral valve replacements (MVRs) has not been documented.

The purpose of this documentation is to determine whether the freedom from SVD for the CE-P and CESAV bioprostheses is similar in MVR. The extensive experience with the CE-SAV bioprosthesis at the University of British Columbia is compared with the CE-P mitral prosthesis experience from 7 European and Canadian centers. ${ }^{12-19}$ The study compares structural failure diagnosed only at reoperation explant for the evaluation. The CE-SAV experience at the University of British Columbia was used with exclusion of 24 patients in whom the diagnosis was made without reoperation and 37 patients in whom stent dehiscence was diagnosed at reoperation. The stent dehiscence failure mode was controlled by a manufacturing process change made in 1986 and 1987 (detail provided in the "Discussion").

The CE-SAV porcine bioprosthesis was introduced by Carpentier and colleagues ${ }^{20}$ in 1982 with several considered improvements over the CE-Standard bioprosthesis, namely supra-annular configuration to reduce transvalvular gradients, optimized stent flexibility to reduce tissue stress, improved tissue preservation with reduction of glutaraldehyde fixation pressure to 2 $\mathrm{mm} \mathrm{Hg}$, and reduction of strut height of the mitral model so as to minimize protrusion within the ventricular cavity. The CE-P pericardial prosthesis was also introduced in 1982 but primarily for aortic valve replacements to facilitate optimum hemodynamics in smaller aortic sizes. The leaflets of the CE-P prosthesis are bovine pericardium fixed without pressure in glutaraldehyde and produced by computer-aided design for optimal leaflet-to-stent matching. The leaflets achieve satisfactory coaptation without stent-post sutures used with first-generation pericardial prostheses. Both the CE-SAV and CE-P valves have the same structural support with an Elgiloy wire stent (Elgiloy Ltd, Elgin, Ill) to reduce stress on the tissue by providing flexibility. The tissue of both prostheses is treated with the surfactant polysorbate 80 , an antimineralization agent.

\section{Patients and methods}

The CE-SAV porcine bioprosthesis was implanted in 1266 overall MVRs (isolated mitral, 1066; mitral in multiple, 200 replacements). The CE-P pericardial bioprosthesis was implanted in 429 overall MVRs (isolated mitral, 328; mitral in multiple, 101 replacements). The mean age of the total patients was $64.2 \pm 12.2$ years for the CE-SAV population and $60.7 \pm 11.7$ years for the CE-P population $(P=.0001)$. The demographics of the patient populations, detailed in Table I, are generally similar. The 2 patient populations incorporated coronary artery bypass (32.5\% [412] and 14.9\% [64], respectively, for CE-SAV and CE-P). This parameter was dissimilar.

The patient populations have been divided into 5 age groups: 40 years or younger, 41 to 50 years, 51 to 60 years, 61 to 70 years, and older than 70 years. The follow-up was $98.6 \%$ complete for CE-P and $97.8 \%$ for CE-SAV. The CE-P documentation was completed to late 1997 and the CE-SAV evaluation was completed in a 6-month closing interval in 1996.

The definition of SVD incorporates all features designated in the "Guidelines for Reporting Morbidity and Mortality After Cardiac Valvular Operations,"21 but for this analysis only SVD diagnosed at explant reoperation was considered for evaluation. The CE-SAV population, whose bioprostheses were implanted in the single center, had excluded 24 patients in whom the diagnosis was made without reoperation and 37 patients with stent dehiscence (in whom the diagnosis was made at reoperation) controlled by alteration in the manufacturing process 12 years ago. The SVD in the CE-P population diagnosed without reoperation is not known.

SVD was compared between the 2 bioprostheses by assessment of actuarial and actual freedom from SVD by the specifically stated age groups. The cases at risk are designated in all figures illustrating freedom from SVD and patient survival.

The Kaplan-Meier method was used to estimate the actuarial freedom from SVD and patient survival, and the log rank statistic test was used to compare the survival curves between the 2 bioprosthesis types for each specific age group. The 
Volume 118, Number 2

Table I. Demographics of patient populations

\begin{tabular}{|c|c|c|c|c|c|c|}
\hline & \multicolumn{3}{|c|}{$C E-P$} & \multicolumn{3}{|c|}{$C E-S A V$} \\
\hline & Mitral (\%) & Multiple (\%) & Combined (\%) & Mitral (\%) & Multiple (\%) & Combined (\%) \\
\hline Gender (female) & 59.2 & 57.8 & 58.9 & 61.3 & 53.5 & 60.0 \\
\hline \multicolumn{7}{|l|}{ Age group (y) } \\
\hline $0-40$ & 9.3 & 6.9 & 8.7 & 5.4 & 4.5 & 5.3 \\
\hline $41-50$ & 6.9 & 3.9 & 6.2 & 8.7 & 8.0 & 8.6 \\
\hline $51-60$ & 27.3 & 21.6 & 26.0 & 17.1 & 11.0 & 16.1 \\
\hline $61-70$ & 38.7 & 42.2 & 39.5 & 35.5 & 32.0 & 34.9 \\
\hline$>70$ & 17.7 & 25.5 & 19.5 & 33.3 & 44.5 & 35.1 \\
\hline \multicolumn{7}{|l|}{ Valve size (mm) } \\
\hline 25 & 1.8 & 4.9 & 2.5 & 10.4 & 14.0 & 11.0 \\
\hline 27 & 36.9 & 37.3 & 37.0 & 34.5 & 34.5 & 34.5 \\
\hline 29 & 39.9 & 39.2 & 39.8 & 31.9 & 34.0 & 32.2 \\
\hline 31 & 18.3 & 18.6 & 18.4 & 16.1 & 13.5 & 15.7 \\
\hline 33 & 3.0 & 0 & 2.3 & 6.7 & 3.5 & 6.2 \\
\hline Concomitant CABG & 15.8 & 11.9 & 14.9 & 34.6 & 21.5 & 32.5 \\
\hline $\begin{array}{l}\text { Previous valve } \\
\text { operation }\end{array}$ & 27.7 & 17.8 & 25.4 & 17.3 & 23.5 & 18.2 \\
\hline
\end{tabular}

$C A B G$, Coronary artery bypass grafting.

reported $P$ values are 2 -sided. The actual freedom from SVD was determined by an analog of the Kaplan-Meier method, cumulative incidence, to estimate the risk probabilities. ${ }^{22,23}$ The Cox regression analysis was used to evaluate the influence of age, gender, valve size, prosthesis type, and coronary artery bypass as risk factors of SVD. The influence of age was determined as both a continuous and a categoric variable. The variables are reported as odds ratios with the $95 \%$ confidence limits (CI) and the designated $P$ values.

\section{Results}

The independent risk factors of SVD by multivariate analysis for the overall MVR group were age and age groups and prosthesis type (CE-SAV > CE-P) (Table II). Valve size, gender, and coronary artery bypass were not independent predictors of SVD. The prosthesis type either in isolated replacement or multiple replacement was not predictive of SVD.

The actuarial freedoms from SVD for overall MVRs are presented in Table III and Figs 1 and 2; for all age groups, except those older than 70 years, the freedom was greater for CE-P than for CE-SAV bioprostheses $(P=.0001)$. For the 61- to 70-year age group, the actuarial freedom for CE-SAV valves was $75.2 \% \pm 3.7 \%$ and for CE-P valves, 95.2\% $\pm 2.1 \%(P=.0001)$. For the 51- to 60-year group, the actuarial freedom for CESAV valves was $69.4 \% \pm 4.5 \%$ and for CE-P valves, $84.3 \% \pm 5.0 \%(P=.0424)$.

The actuarial freedom from SVD for the patients 60 years of age and younger is designated in Fig 2. For overall MVR, the actuarial freedom was $64.7 \% \pm 3.3 \%$ for CE-SAV valves and $83.9 \% \pm 3.7 \%$ for $\mathrm{CE}-\mathrm{P}$ valves $(P=.0001)$.

The actual freedom from SVD for overall MVR is shown in Table IV and Figs 3 and 4 for all age groups. In Fig 4 the actual freedom from SVD for the patients 60 years of age or younger is designated for CE-P and CE-SAV bioprostheses.

The pathologic features of the explanted prostheses for both CE-P and CE-SAV valves are detailed in Table V. Dystrophic calcification (only) occurred in $70.4 \%$ of CE$\mathrm{P}$ and $16.9 \%$ of CE-SAV prostheses, and leaflet tear without calcification in $18.5 \%$ and $26.6 \%$, respectively. The combination of calcification and leaflet tear occurred in $11.1 \%$ of CE-P and $56.5 \%$ of CE-SAV prostheses.

Patient survival is illustrated in Table VI. The patient survival in the overall MVRs is differentiated in the 61to 70-year age group only for CE-P > CE-SAV ( $P=$ $.0001)$. The patient survival for the 60 or younger age group does not differentiate between the prostheses for overall MVRs (no significant difference). The reoperative mortality for CE-SAV valves was $1.3 \%$ for MVR and $11.5 \%$ for MVR and mitral in multiple (combined MVR and mitral in multiple, $2.8 \%$ ). The reoperative mortality was not collected for the CE-P prostheses.

\section{Discussion}

SVD remains the major valve-related complication of biologic tissue. This documentation reveals that the performance of the CE-P pericardial bioprosthesis is superior, overall, to that of the CE-SAV porcine bioprosthesis with regard to freedom from SVD in MVR 
Table II. Results of Cox regression analysis for predictors of SVD diagnosed at explant reoperation for the overall MVR population

\begin{tabular}{|c|c|c|c|c|}
\hline Variable & Category & Odds ratio & $C I$ & $\mathrm{P}$ value \\
\hline \multicolumn{5}{|c|}{ Model I (age as continuous variable) } \\
\hline \multirow[t]{2}{*}{ Valve type } & CE-P & Baseline & & \\
\hline & CE-SAV & 2.966 & $1.983-4.434$ & .0001 \\
\hline \multirow[t]{2}{*}{ Age } & & 0.962 & $0.953-0.971$ & .0001 \\
\hline & e as catego & & & \\
\hline \multirow[t]{2}{*}{ Valve type } & CE-P & Baseline & & \\
\hline & CE-SAV & 2.891 & $1.930-4.331$ & .0001 \\
\hline \multirow[t]{4}{*}{ Age } & $0-40$ & Baseline & & \\
\hline & $41-50$ & 0.855 & $0.551-1.325$ & .483 \\
\hline & $51-60$ & 0.598 & $0.393-0.910$ & .016 \\
\hline & $>60$ & 0.320 & $0.211-0.484$ & .0001 \\
\hline
\end{tabular}

CI, Confidence interval.

Table III. Actuarial freedom from SVD of overall MVR by age groups

\begin{tabular}{|c|c|c|c|c|c|c|}
\hline \multirow[b]{2}{*}{ Age groups (years) } & \multicolumn{2}{|c|}{ Number $(n)$} & \multicolumn{2}{|c|}{ Percent freedom at 5 years $(n)$} & \multicolumn{2}{|c|}{ Percent freedom at 10 years $(n)$} \\
\hline & $C E-P$ & $C E-S A V$ & $C E-P$ & $C E-S A V$ & $C E-P$ & $C E-S A V$ \\
\hline$\leq 40^{*}$ & 38 & 67 & $97.1 \pm 2.8(34)$ & $93.9 \pm 3.4(44)$ & $79.7 \pm 7.6(16)$ & $59.5 \pm 7.8(18)$ \\
\hline $41-50 *$ & 109 & 27 & $100(26)$ & $95.5 \pm 2.2(78)$ & $91.1 \pm 6.1(10)$ & $60.7 \pm 5.9(34)$ \\
\hline $51-60 *$ & 108 & 204 & $98.8 \pm 1.2(78)$ & $100(152)$ & $84.3 \pm 5.0(30)$ & $69.4 \pm 4.5(54)$ \\
\hline $61-70 *$ & 171 & 442 & $100(128)$ & $98.4 \pm 0.8(223)$ & $95.2 \pm 2.1(46)$ & $75.2 \pm 3.7(69)$ \\
\hline$>70$ & 85 & 444 & $100(55)$ & $100(136)$ & $100(9)$ & $91.5 \pm 3.2(34)$ \\
\hline
\end{tabular}

Numbers at risk at 5 and 10 years are given in parentheses.

$* P<.05$, CE-P $>$ CE-SAV bioprostheses.

surgery. No controlled studies have compared the second-generation CE-P pericardial prostheses with the second-generation porcine bioprostheses, namely, the CE-SAV and the Hancock II valves in either aortic valve replacement or MVR.

The documentation afforded from the literature does not seem to differentiate these prostheses in the aortic position after 10 and 12 years of evaluation. The freedom from SVD beyond 10 years is incomplete. The freedom from SVD for aortic valve replacement at 10 years and 12 years with the CE-SAV bioprosthesis was $91 \%$ and $83 \%$, respectively, overall, with a mean age of 65 years. ${ }^{16}$ In other series with similar mean ages, the freedom from SVD at 10 years was $92 \%$ for the Hancock II porcine bioprosthesis and ranged from $87 \%$ to $100 \%$ for the CE-P bioprosthesis. ${ }^{4-12}$ The series reported by Neville and colleagues ${ }^{5}$ revealed a 94\% freedom at 12 years with the aortic CE-P bioprosthesis, but the mean age was 68 years. Banbury and coauthors ${ }^{9}$ reported a freedom from SVD of $82 \%$ at 12 years with the CE-P valve, also in the aortic position, in patients with a mean age of 64 years. Poirier and colleagues ${ }^{11}$ reported CE-P freedom from SVD of $93 \%$ and $80 \%$ at 10 and 14 years, respectively. Further extended reports are required for comparative evaluations.

The current comparative study has been performed only on prostheses explanted for SVD. The follow-up from the CE-P centers included SVD diagnosed at reoperation. The CE-SAV experience at the University of British Columbia includes an additional 66 cases that were not included in reoperation for explant for the study. Of this group, 24 were diagnosed without reoperation and 37 were previously diagnosed with stent dehiscence at reoperation. The stent dehiscence mode of failure was identified in prostheses implanted between 1982 and 1986. The stent dehiscence caused normal-appearing tissue to separate from the origin of the stent post and the resultant release of 2 leaflets with mitral regurgitation as the ultimate consequence. ${ }^{13-16}$ When the prosthesis was introduced in 1982, the tissue had been prepared with the aortic wall being extensively trimmed. With the identification of that stent dehiscence likely being related to extensive aortic wall trimming, the manufacturer altered the way in which the tissue was prepared. In 1986, the manufacturer introduced reduced trimming of the aortic wall of large mitral prostheses, and in 1987 this practice was extend- 


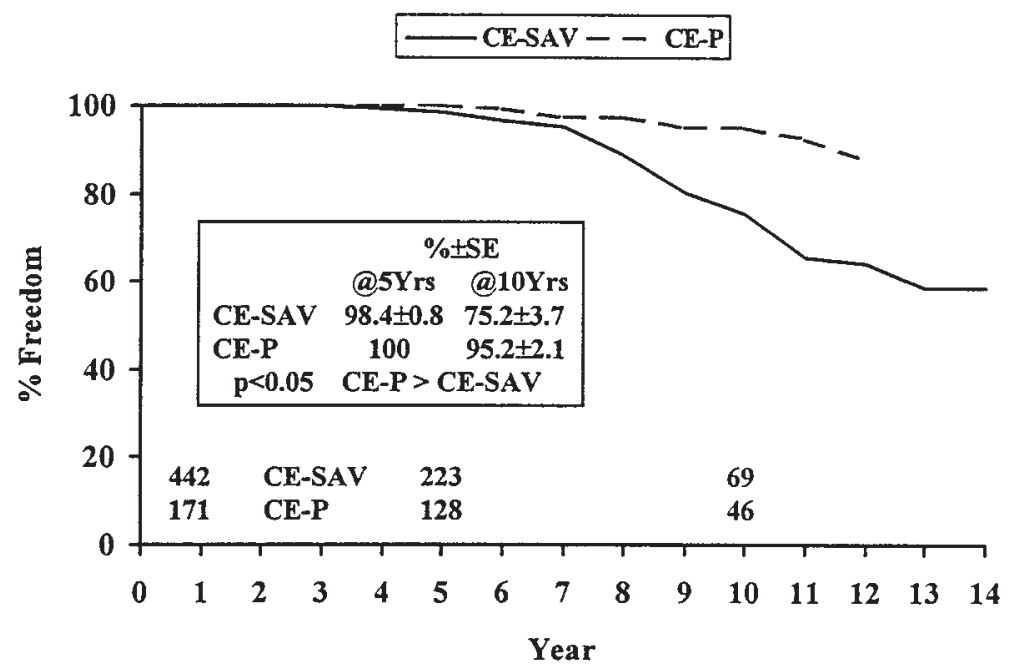

Fig 1. Actuarial freedom from SVD for overall MVR in the 61- to 70-year age group.

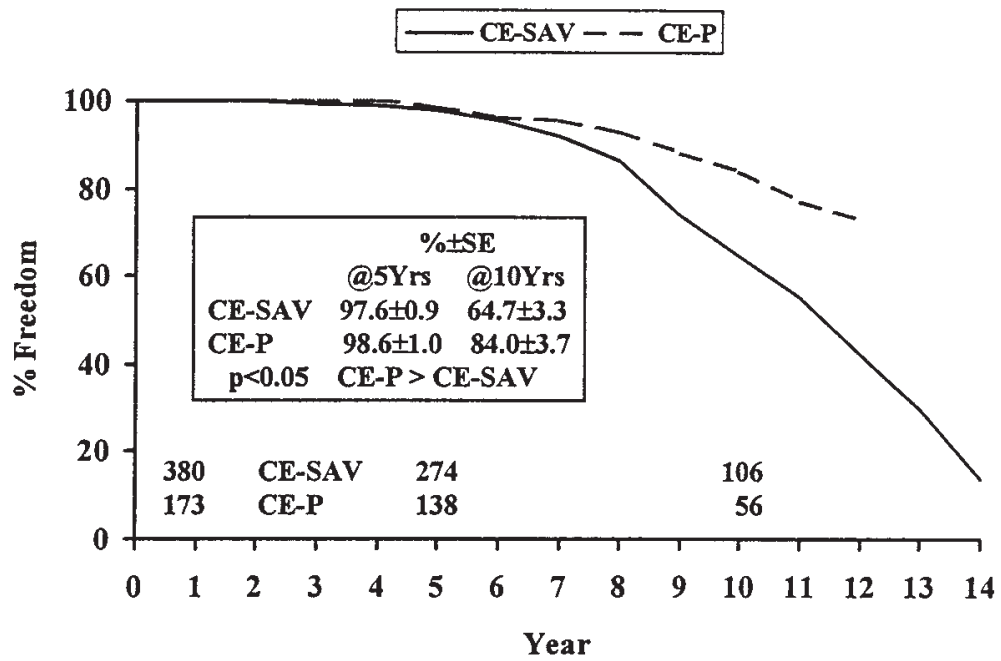

Fig 2. Actuarial freedom from SVD for overall MVR for the age group 60 years and younger.

ed to all sizes of mitral and aortic prostheses. Inasmuch as we believe the problem of early stent dehiscence has been resolved, the cases of stent dehiscence were not incorporated in the analysis to provide an appropriate representation of the current CE-SAV valve performance and to have extended follow-up for comparison.

Documentation of the performance of the CE-P mitral prosthesis has been limited, and the prosthesis has not been widely implanted. In 1995, Pelletier and colleagues ${ }^{10}$ reported on the experience at the Montreal Heart Institute, where the CE-P valve is the biologic prosthesis of choice. The freedom from SVD at 10 years was $79 \%$ for MVR and $77 \%$ for multiple valve replacement. Poirier and colleagues ${ }^{11}$ reported further on this experience, with an $81 \%$ freedom from SVD at 10 years. In 1995, Takahara and coauthors ${ }^{17}$ reported an $84 \%$ freedom from SVD at 9 years. Murakami and associates, ${ }^{18}$ reporting in 1996, indicated that the freedom from SVD in a patient population with a mean age of 57 years was $77 \%$ at 10 years for MVR. Aupart, ${ }^{19}$ Carpentier, ${ }^{20}$ and their colleagues have reported extensively on their experience with the CE-P prosthesis. At 12 years the freedom from SVD was $94 \%$ for the prosthesis in the mitral position. In their multiple replacement population, the freedom for patients 60 years of age or younger was $93 \%$ at 10 years. ${ }^{24}$ 
Table IV. Actual freedom from SVD for overall MVR by age groups

\begin{tabular}{|c|c|c|c|c|c|c|}
\hline \multirow[b]{2}{*}{ Age groups (years) } & \multicolumn{2}{|c|}{ Number $(n)$} & \multicolumn{2}{|c|}{ Percent freedom at 5 years $(n)$} & \multicolumn{2}{|c|}{ Percent freedom at 10 years $(n)$} \\
\hline & $C E-P$ & $C E-S A V$ & $C E-P$ & $C E-S A V$ & $C E-P$ & $C E-S A V$ \\
\hline$\leq 40$ & 38 & 67 & $97.4 \pm 2.6(35)$ & $95.0 \pm 2.8(45)$ & $82.2 \pm 6.7(17)$ & $67.9 \pm 6.4(19)$ \\
\hline $41-50$ & 109 & 27 & $100(27)$ & $96.1 \pm 1.9(79)$ & $92.2 \pm 5.3(11)$ & $69.5 \pm 4.8(35)$ \\
\hline $51-60$ & 108 & 204 & $99.1 \pm 0.9(79)$ & $100(153)$ & $89.8 \pm 3.3(31)$ & $80.0 \pm 3.0(56)$ \\
\hline $61-70$ & 171 & 442 & $100(129)$ & $98.9 \pm 0.5(224)$ & $96.8 \pm 1.4(47)$ & $87.6 \pm 1.9(70)$ \\
\hline$>70$ & 85 & 444 & $100(56)$ & $100(137)$ & $100(10)$ & $96.5 \pm 1.3(35)$ \\
\hline
\end{tabular}

Numbers at risk at 5 and 10 years are given in parentheses.

Table V. Pathology of SVD for CE-P and CE-SAV bioprostheses for MVR

\begin{tabular}{lcc}
\hline & $C E-P$ & $C E-S A V$ \\
\hline Calcification (\%) & 70.4 & 16.9 \\
Leaflet tear (\%) & 18.5 & 26.6 \\
Calcification/leaflet tear (\%) & 11.1 & 56.5 \\
\hline
\end{tabular}

The identified reduced performance of the secondgeneration CE-SAV mitral prosthesis is certainly of concern. The difference in the mean ages of the 2 populations does not afford an opportunity for an overall statement of freedom for MVRs. In the overall MVRs, the actuarial freedom from SVD for CE-P prostheses was superior to that of CE-SAV prostheses for the age groups 40 years and younger, 41 to 50 years, 51 to 60 years, and 61 to 70 years. No significant differences were observed in the age group older than 70 years, but the trend was impressive: $100 \%$ for CE-P bioprostheses and $92 \%$ for CE-SAV bioprostheses at 10 years. The University of British Columbia experience, documenting all SVD cases diagnosed clinically, at autopsy, or at reoperation, was reported in 1997 for the same age groupings. ${ }^{25}$ For MVR the 10-year freedom from SVD was $70 \%$ for the 41 - to 50 -year age group, $59 \%$ for the 51- to 60-year group, and 55\% for the 61- to 70-year group; at 12 years, the freedom from SVD was $87 \%$ for the age group older than 70 years. The freedom from SVD in the elderly is in keeping with previous reports, including the extensive report by Burr and colleagues ${ }^{26}$ from the University of British Columbia. The Hancock II experience, by David, Armstrong, and Sun, ${ }^{12}$ has not been documented by the same age categorization, but the overall freedom from mitral SVD at 12 years was $82 \%$ with a mean age of 65 years.

The actual freedom from SVD for the overall MVRs was also provided to avoid overestimation of the incidence of SVD. ${ }^{22,23}$ The actual analysis accounts for the many patients who died of unrelated causes before the bioprostheses failed, thus providing a better estimate of durability of bioprostheses, especially in patients with reduced expectancy of survival. The observational comparison of actuarial and actual freedom from SVD is important for physicians and surgeons in the decisionmaking process. In summary, the actual freedom at 10 years for CE-P versus CE-SAV prostheses for overall MVR was as follows: for 40 years of age or younger, $82 \%$ versus $68 \%$; for 41 to 50 years, $92 \%$ versus $70 \%$; for 51 to 60 years, $90 \%$ versus $80 \%$; for 61 to 70 years, $97 \%$ versus $88 \%$; and older than 70 years, $100 \%$ versus $97 \%$, respectively.

The cause of the increased degree of failure with the CE-SAV valve is likely contributed to by the prosthesis design. The CE-SAV mitral prosthesis was designed with reduction in strut height to minimize protrusion within the ventricular cavity. The concept of the lowprofile bioprosthesis has been given consideration in assessing the mode of failure in the long-term of the low-profile St Jude Medical BioImplant (Liotta) porcine bioprosthesis (St Jude Medical Inc, St Paul, Minn). ${ }^{27,28}$ Valve regurgitation has been identified by Ius and colleagues ${ }^{28}$ as the usual mode of failure of the Liotta prosthesis in the mitral position. These authors have identified that commissural tearing of the right coronary cusp was the most common cause of valve regurgitation and occurred even in the presence of minimal calcification. The pathologic findings imply bulging of the right coronary cusp, which increases the risk of increased stress at the commissures, accelerating calcification and tearing. The low profile design of the CE-SAV mitral prosthesis may also be a contributing factor to structural failure and requires further detailed pathologic assessment. The CE-P bioprosthesis, on the other hand, is designed by computer-generated leaflet sizing according to stent size so that commissural stress is minimal. The design of these 2 prostheses is likely the differentiating factor in the differences in clinical performance at 10 years.

The actual pathologic mode of failure has been identified to be dissimilar. The majority of CE-P failures are from primary dystrophic calcification, whereas for CE- 


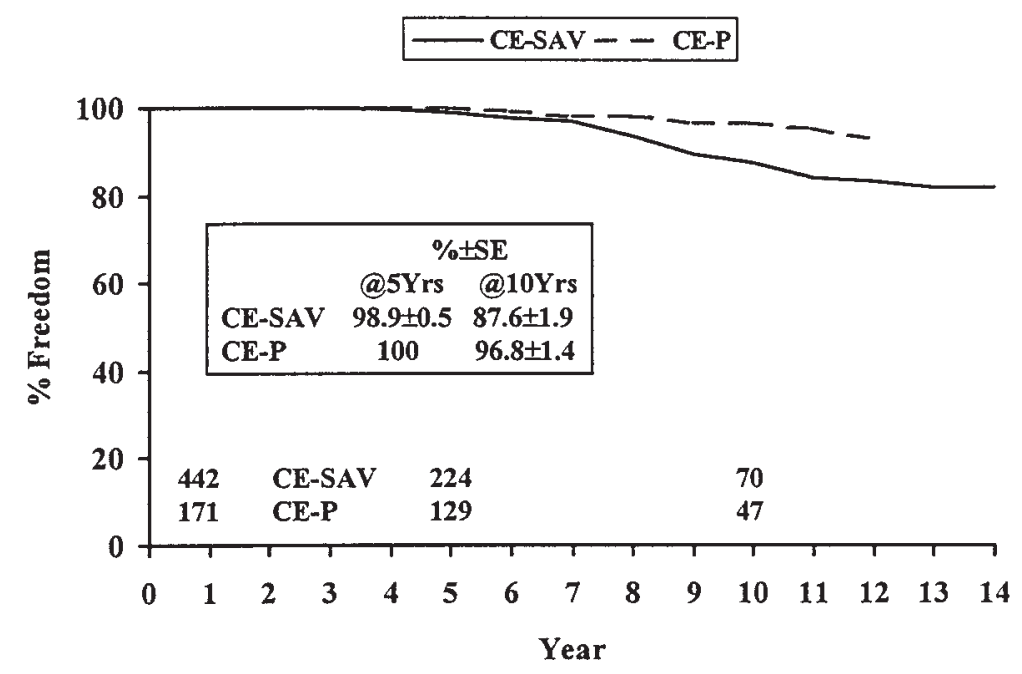

Fig 3. Actual freedom from SVD for overall MVR for the 61- to 70-year age group.

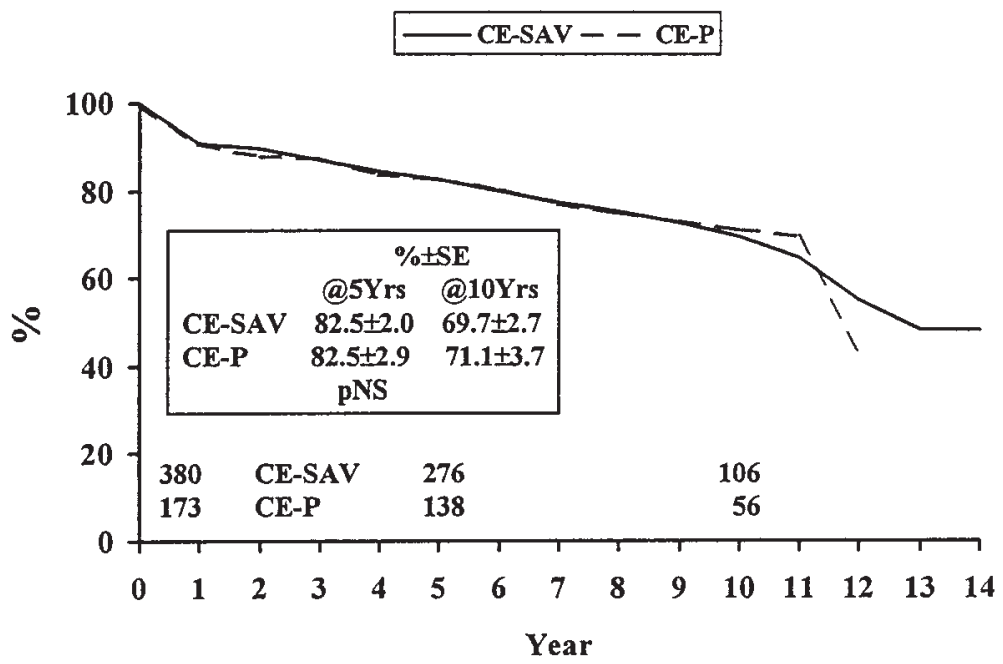

Fig 4. Actual freedom from SVD for overall MVR for the age group 60 years of age or younger.

Table VI. Patient survival for overall MVR by age groups

\begin{tabular}{|c|c|c|c|c|c|c|}
\hline \multirow[b]{2}{*}{ Age groups (years) } & \multicolumn{2}{|c|}{ Number $(n)$} & \multicolumn{2}{|c|}{ Percent freedom at 5 years $(n)$} & \multicolumn{2}{|c|}{ Percent freedom at 10 years $(\mathrm{n})$} \\
\hline & $C E-P$ & $C E-S A V$ & $C E-P$ & $C E-S A V$ & $C E-P$ & $C E-S A V$ \\
\hline$\leq 40$ & 38 & 67 & $94.6 \pm 3.7(34)$ & $86.3 \pm 4.4(45)$ & $86.7 \pm 6.4(16)$ & $74.9 \pm 7.2(18)$ \\
\hline $41-50$ & 109 & 27 & $96.3 \pm 3.6(26)$ & $83.5 \pm 3.7(78)$ & $77.7 \pm 9.3(10)$ & $77.3 \pm 4.3(34)$ \\
\hline $51-60$ & 108 & 204 & $74.8 \pm 4.2(78)$ & $80.7 \pm 2.8(153)$ & $64.2 \pm 4.8(30)$ & $64.1 \pm 3.8(54)$ \\
\hline $61-70^{*}$ & 171 & 442 & $75.4 \pm 3.3(128)$ & $65.1 \pm 2.4(224)$ & $56.8 \pm 4.0(46)$ & $38.0 \pm 2.9(70)$ \\
\hline$>70$ & 85 & 444 & $64.7 \pm 5.2(55)$ & $55.8 \pm 2.8(136)$ & $25.6 \pm 5.9(9)$ & $28.6 \pm 3.2(34)$ \\
\hline
\end{tabular}

Numbers at risk at 5 and 10 years are given in parentheses.

$* P<.05$, CE-P $>$ CE-SAV bioprostheses.

SAV valves the primary cause is the combination of calcification and leaflet tearing. These findings indicate that the patients with CE-P SVD will present with mitral stenosis and those with CE-SAV SVD with mitral regurgitation. The CE-SAV patient is more likely to have acute symptoms whereas the CE-P patient may 
have insidious chronic valvular stenosis. Planned echocardiographic surveillance of the CE-P prosthesis will be a greater need than for the CE-SAV prosthesis. These failure modes could change the clinical performance by the 15 - and 20 -year intervals.

This study concludes that at 10 years the incidence of SVD is greater for the CE-SAV porcine bioprosthesis than for the CE-P pericardial bioprosthesis. The prosthesis designs are likely the contributing factors to these differences. Long-term evaluation to 15 and 20 years is a necessity.

\section{REFERENCES}

1. Fann JI, Miller DC, Moore KA, et al. Twenty-year clinical experience with porcine bioprostheses. Ann Thorac Surg 1996;62:1301-12.

2. Burdon TA, Miller DC, Oyer PE, et al. Durability of porcine valves at fifteen years in a representative North American patient population. J Thorac Cardiovasc Surg 1992;103:238-52.

3. Jamieson WRE, Burr LH, Janusz MT, et al. Carpentier-Edwards standard and supra-annular porcine bioprostheses: comparison of technology on structural valve deterioration. Ann Thorac Surg 1998;66:40-3.

4. Aupart MR, Neville P, Dreyfus X, Meurisse Y, Sirinelli A, Marchand M. The Carpentier-Edwards pericardial aortic valve: intermediate results in 420 patients. Eur J Cardiothorac Surg 1994;8:277-80.

5. Neville PH, Aupart MR, Diemont FF, Sirinelli AL, Lemoine EM, Marchand MA. Carpentier-Edwards pericardial bioprosthesis in aortic or mitral position: a twelve year experience. Ann Thorac Surg 1998;66:S143-7.

6. Aupart MR, Sirinelli AL, Diemont FF, Meurisse YA, Dreyfus XB, Marchand MA. The last generation of pericardial valves in the aortic position: ten-year follow-up in 589 patients. Ann Thorac Surg 1996;61:615-20.

7. Pellerin M, Mihaileanu S, Couetil JP, et al. Carpentier-Edwards pericardial bioprosthesis in aortic position: long-term follow-up 1980 to 1994. Ann Thorac Surg 1995:60:S292-5.

8. Cosgrove DM, Lytle BW, Taylor PC, et al. The CarpentierEdwards pericardial aortic valve: ten-year results. J Thorac Cardiovasc Surg 1995;110:651-62.

9. Banbury MK, Cosgrove DM, Lytle BW, Smedira NG, Sabik JF, Saunders CR. Long-term results of the Carpentier-Edwards pericardial aortic valve: a twelve year follow-up. Ann Thorac Surg 1998;S73-6.

10. Pelletier LC, Carrier M, Leclerc Y, Dyrda I. The CarpentierEdwards Pericardial bioprosthesis: clinical experience with 600 patients. Ann Thorac Surg 1995;60:S297-302.

11. Poirier N, Pelletier LC, Pellerin M, Carrier M. Fifteen year experience with the Carpentier-Edwards pericardial bioprosthesis. Ann Thorac Surg 1998;66:S57-61.

12. David TE, Armstrong S, Sun Z. The Hancock II bioprosthesis at twelve years. Ann Thorac Surg 1998;66:S95-8.

13. Jamieson WRE, Burr LH, Miyagishima RT, et al. Structural deterioration in Carpentier-Edwards standard and supra-annular porcine bioprostheses. Ann Thorac Surg 1995;60:S241-7.

14. Jamieson WRE, Burr LH, Tyers GFO, et al. Carpentier-Edwards supra-annular porcine bioprosthesis: clinical performance to twelve years. Ann Thorac Surg 1995;60:S235-40.

15. Jamieson WRE, Burr LH, Tyers GFO, Munro AI. Carpentier-
Edwards standard and supra-annular porcine bioprostheses: 10 year comparison of structural valve deterioration. J Heart Valve Dis 1994;3:59-65.

16. Jamieson WRE, Ling H, Burr LH, et al. Carpentier-Edwards supra-annular porcine bioprosthesis: evaluation over 15 years. Ann Thorac Surg 1998;66:S49-52.

17. Takahara Y, Sudou Y, Murayama H, Nakamura T. Long-term evaluation of the Carpentier-Edwards pericardial bioprosthesis. Nippon Kyobu Geka Gakkai Zasshi 1995;43:1097-102.

18. Murakami T, Eishi K, Nakano S, et al. Aortic and mitral valve replacement with the Carpentier-Edwards pericardial bioprosthesis: 10 year results. J Heart Valve Dis 1996;5:45-9.

19. Aupart MR, Neville PH, Hammami S, Sirinelli AL, Meurisse YA, Marchand MA. Carpentier-Edwards pericardial valves in the mitral position: ten-year follow-up. J Thorac Cardiovasc Surg 1997:113:492-8.

20. Carpentier A, Dubost C, Lane E, et al. Continuing improvements in valvular prostheses. J Thorac Cardiovasc Surg 1982;83:27-42.

21. Edmunds LH Jr, Clark RE, Cohn LH, Grunkemeier GL, Miller DC, Weisel RD, for the Ad Hoc Liaison Committee for Standardizing Definitions of Prosthetic Heart Valve Morbidity of The American Association for Thoracic Surgery and The Society of Thoracic Surgeons. Guidelines for reporting morbidity and mortality after cardiac valvular operations. J Thorac Cardiovasc Surg 1996;112:708-11.

22. Grunkemeier GL, Jamieson WRE, Miller DC, Starr A. Actuarial versus actual risk of porcine structural valve deterioration. J Thorac Cardiovasc Surg 1994;108:709-18.

23. Grunkemeier GL, Anderson RP, Miller DC, Starr A. Time-related analysis of nonfatal heart valve complications: cumulative incidence (actual) versus Kaplan-Meier (actuarial). Circulation 1997;96(9 Suppl):II70-5.

24. Aupart MR, Babuty DG, Guesnier L, Meurisse YA, Sirinielli AL, Marchand MA. Double valve replacement with the CarpentierEdwards pericardial valve: 10 year results. J Heart Valve Dis 1996;5:312-6.

25. Jamieson WRE, Ling H, Burr LH, Fradet GJ, Miyagishima RT, Lichtenstein SV, et al. Carpentier-Edwards bioprosthesis: structural deterioration by age groups. Asian Cardiovasc Thorac Ann 1997:5:193-8.

26. Burr LH, Jamieson WRE, Munro AI, et al. Structural valve deterioration in elderly patient populations with the CarpentierEdwards standard and supra-annular porcine bioprostheses: a comparative study. J Heart Valve Dis 1992;1:87-91.

27. Bortolotti U, Milano A, Mazzucco A, et al. Influence of prosthetic design on durability of the Liotta porcine valve in the mitral position. Ann Thorac Surg 1990:50:734-8.

28. Ius P, Thiene G, Minarini M, et al. Low-profile porcine bioprosthesis (Liotta): pathologic findings and mode of failure in the long-term. J Heart Valve Dis 1996;5:323-7.

\section{Discussion}

Dr Walter Wolfe (Durham, $N C$ ). I first would agree that death is final. This paper cries out for echocardiography, because echocardiography is going to be the best means of evaluating failure of these valves.

This paper contains a great deal of information and merits close study. At Duke, we stopped using tissue valves in the mitral position for a long time in the 1980s, for a number of 
reasons. The history of these valves remains unsettled, but they are known to fail. Early on, the recommendation was that patients receive anticoagulation for 1 month and then 2 months. Did any of these patients receive anticoagulation over a period of time?

Dr Jamieson. Generally the patients received anticoagulant therapy for approximately 4 to 6 weeks in the various centers, although there is some variation within the centers. If the patients remained in sinus rhythm, anticoagulation therapy would be discontinued and replaced with antiplatelet therapy. Those who had chronic atrial fibrillation would continue to receive anticoagulants. Unfortunately, because there were 8 centers, I cannot provide exact figures.

Dr Wolfe. Currently the operation of choice in the mitral valve is a repair, but perhaps concern over the use of a certain prosthesis in the mitral position is no longer necessary.

I still believe these valves have several problems. Early on, after the pericardial valve became available, we initially inserted it without echocardiographic evaluation. We know that echocardiography has improved immensely in the past 10 years. We started seeing a gradient across the valve in the mitral position, which we believed was a problem with stiffness in the leaflets, and it was for that reason that we stopped using the valve in the mitral position. In the future, as you monitor these patients, you will need to look for a progressive gradient in the mitral position.

In this study, stenosis is the principal cause for failure, as you pointed out. I wonder whether the fixation process or this stiffness might lead then to this calcification. Another problem is leaflet tear, and it appears to be more common in the Carpentier-Edwards porcine valve, although there have been manufacturing improvements. My concern is that the cardiologists regard these valves almost as if they were native valves. In the aortic position they start seeing a gradient across the valve of 10,20 , or $30 \mathrm{~mm} \mathrm{Hg}$ in 4 or 5 years, and they do not send the patient for valve removal. The patient has structural valve failure but not clinical failure. Later on, the valve leaks or suddenly tears and the situation is urgent.
Can you comment on the reason these valves failed and when they had to be removed?

Dr Jamieson. In approximately $60 \%$ of these porcine valves, failure was caused by a combination of calcification and subsequent tear. That was not the excessive calcification that we know occurs in these pericardial valves. The porcine valve failure is indicated by regurgitation. Only approximately $16 \%$ presented primarily with pure calcification without a tear, which was the opposite of the situation in the pericardial valves.

Dr Wolfe. In 1994, when we published our series, we had 10 years of survival data on the valves, $57 \%$ in the mitral position, $76 \%$ in the aortic, and $95 \%$ in the tricuspid position. In the patients older than 60 , we had a $90 \% 10$-year valve survival. One of the interesting things we observed was that the larger mitral valves seemed to fail earlier, that is, valve sizes 31 or greater had an earlier failure rate than the smaller valves. Do you have a comment regarding that in your data?

Dr Jamieson. Valve size was not an independent predicator of failure.

We have 15 years of data with about a $90 \%$ valve survival in the aortic position in patients older than 60 . However, in the mitral position in patients younger than 60 , the valve survival is much less. I favor a mechanical valve in the mitral position much of the time, even in healthy patients, because these tissue valves will fail in 10 to 12 years and the patient will return for a replacement.

Dr Wolfe. What was the explant mortality? Removal of these valves can be a difficult task.

Dr Jamieson. The explant mortality in the Vancouver series was $3 \%$ in the overall mitral population. I do not have the full data from all the centers to tell you the complete figure.

Dr Wolfe. I certainly agree that the principal mode of failure will be stenosis with the pericardial valve, and that will be better tolerated by the patient. Consequently, you are going to encounter what I would call structural valve failure earlier in the follow-up period, before you explant. Therefore, serial echocardiographic data in the follow-up of these patients is going to be extremely important. 